\title{
Discrepancies between post-disaster relocation policy and implementation in the Philippines
}

3 Corresponding author: Shaye Palagi, $\mathrm{PhD}$ candidate; Department of Civil, Environmental and Architectural 4 Engineering; University of Colorado Boulder; 1111 Engineering Drive, Boulder, CO 80309 USA, 5 shaye.palagi@colorado.edu

6 Dr. Amy Javernick-Will, Associate Professor; Department of Civil, Environmental and Architectural 7 Engineering; University of Colorado Boulder; 1111 Engineering Drive, Boulder, CO 80309 USA, 8 amy.javernick@colorado.edu

9 Abstract: It is common for recovery policies to be crafted following disasters, such as the relocation of 10 exposed populations, but rare for policy intent to be fully realized. While critiques center on failed 11 outcomes, there is a dearth of knowledge regarding implementation, which encompasses the intermediary

12 processes between policy formation and outcomes. Without an understanding of implementation, it is 13 difficult to identify actionable opportunities for change. Using document-based classic content analysis, 14 narrative analysis, and process mapping, this study systematically compared policy and implementation to 15 identify discrepancies unfolding throughout typhoon-induced relocation in the Philippines. Two types of 16 discrepancies emerged: unfulfilled, where they were covered in policy but not present in implementation, 17 or added, where they were un- or under-addressed in policy but added by necessity during implementation.

18 Analysis revealed that community services and infrastructure were added discrepancies, while 19 development-oriented objectives were unfulfilled. Second, one well-documented relocation discrepancy, 20 water supply, was analyzed in-depth using implementation analysis, revealing delayed and, at-times, 21 disorganized project management was driven by a lack of ownership and goal clarity. Shifting strategies 22 throughout implementation indicate a need to further investigate the implementation of risk reduction and 23 resilience-oriented policies in post-disaster contexts.

\section{Introduction}

25 Disasters are often followed by rhetoric espousing resilience, yet sometimes intended recovery outcomes 26 go unfulfilled. The divide between post-disaster envisioned and enacted outcomes may be the largest for 27 relocation, when exposed residents are transferred to newly developed land and initial policies are imbued 28 with optimism, but where beneficiaries sometimes receive inadequate housing and infrastructure outcomes. 
29 Post-disaster policies that aim to produce positive outcomes may not lead to functional or livable outcomes

30 for relocation beneficiaries for a host of reasons. For example, households relocated following the 2004

31 Indian Ocean tsunami reported poor housing quality, few communal spaces, and inaccessible social services

32 (Manatunge and Abeysinghe 2017). Even where quality is satisfactory, distance between the relocation site

33 and prior community may be prohibitively far to make regular and affordable trips (Bavinck et al. 2015).

34 When outcomes are intolerable, beneficiaries abandon relocation sites altogether (Doberstein and Stager

35 2013). Rejected relocation projects are likely to deteriorate into unoccupied relics of poor post-disaster

36 coordination, participation, and financial management (Sanderson and Sharma 2008).

37 Simplistically, post-disaster relocation is a transition from idealized intent to results. Theoretically,

38 ambitious expectations are articulated into policies, policies are implemented until they produce outputs

39 (e.g. number of houses), and outputs are coalesced into meaningful outcomes (e.g. community resiliency).

40 Where this is not true - where envisioned relocation outcomes never materialize — research has focused on

41 the discrepancy between initial intent and end results rather than intermediary processes. Consequently, it

42 is still "fair to say that far more sensitivity to the complexities of the resettlement process is needed" (Oliver-

43 Smith 1991, pg. 13). Especially where disasters catalyze new and specific recovery policies, there is an

44 opportunity to longitudinally dissect priorities throughout policy formation and implementation. In resource

45 limited contexts, goals may extend beyond recovery and into comprehensive, development-related 46 objectives.

47 This research adopts a different comparison, one between policy and implementation. With the 48 hypothesis that a simplified juxtaposition will reveal significant differences between the two and, perhaps, 49 even imperfections in the policy itself, the first phase of inquiry explores: (RQ1) What are the discrepancies

50 between relocation policy and its implementation? Identifying differences between policy and

51 implementation will expose problematic aspects of relocation for future policy formation, yet identification

52 alone does not address the full complexity of achieving policy intent. Relocation implementation, like the

53 implementation of other public policies, is complex, involving clusters of responsibilities and activities

54 across numerous scales of action, i.e. individual, organizational, and institutional (Hill and Hupe 2006). 
55 Therefore, a second research phase seeks to characterize the process: (RQ2) Once discrepancies were 56 identified, how did the implementation process evolve? Following the identification of discrepancies in the

57 first research question, one aspect of relocation (the development of permanent water supply) was identified

58 for an in-depth, narrative investigation to elucidate implementation complexities.

59 Although much of the domain in question - post-disaster housing and civil infrastructure systems

$60-$ is physical, this research views post-disaster planning and construction through the social and 61 organizational lens of implementation analysis. The study of "what happens between the establishment of 62 policy and its impact in the world of action" (O'Toole 2000, pg. 273) has demonstrated an ability to identify

63 process dynamics and bottlenecks. In recent years, implementation analysis has been applied to investigate

64 and further the implementation of resilience and, more sparingly, the implementation of post-disaster 65 reconstruction (e.g., Blakely and Fisher 2017; Nohrstedt and Parker 2014). To draw together existing 66 relevant literature, this paper begins with a theoretical review of implementation. We present the case study 67 and context (post-typhoon relocation in the Philippines) and then describe the methods used to analyze 68 qualitative data and address each research question. Results for each question are followed by a discussion 69 of how the findings contribute to research and practice.

70 Background

71 Following natural hazard-related disasters (the focus of this study, although the non-naturalness of 72 environmental disasters is acknowledged (Cannon 1994)), often event-specific policies are formed to guide 73 recovery. After policy formation, implementation comprises the coordination and planning efforts required 74 to actualize policy intent. The general intent of post-disaster relocation policy is to remove vulnerable 75 populations from hazardous locations by transforming undeveloped land into adequate public housing, 76 complete with basic social and infrastructure services, although few, if any, "successful" relocation projects 77 exist (Oliver-Smith 2020). To build the case for investigating relocation implementation, this study is 78 grounded both in the sub-field of implementation analysis as well as complementary resilience, post79 disaster, and displacement discourse.

80 Implementation analysis 
81 Implementation analysis is a potential bridge between the complementary fields of public policy and

82 organizational studies, albeit an under-utilized one (Bozeman 2013). Although the study of implementation

83 gained traction throughout the $20^{\text {th }}$ century, Pressman and Wildavsky's (1984) examination of a mid-century

84 American economic development program is most often credited as the seminal implementation study

85 (Saetren 2005). They contended that when intended results do not materialize out of legitimately-crafted

86 and well-resourced policies, the problem lies with implementation and, more specifically, the sheer number

87 of steps required from policy to outcome (Pressman and Wildavsky 1984). They concluded that the chance

88 of successful implementation of any public policy is extraordinarily low.

89 Critiques of Pressman and Wildavsky (and similar theoretical perspectives) center around their

90 underlying assumptions, namely that the policy in-question is good (i.e. comprehensive, actionable,

91 benevolent, etc.) and, from the starting point of good policy, implementation is simply a matter of a linear

92 series of steps by subordinate organizations and bureaucrats (Bowen 1982; Hupe 2011). Mosse (2004)

93 contended that, because the policy ambitions encounter competing institutional and system goals, policy is

94 inherently unable to be implemented in practice as intended. Nevertheless, the context-thick lens of

95 implementation serves as a bridge not only between public policy and organizational studies, but between

96 diverse disciplines whose domains impact the effort of organizations to implement public policies.

97 Implementation analysis frames reconstruction as a social and multi-organizational process rather than a

98 technical endeavor alone.

99 Relocation implementation

100 Numerous scholars have placed case studies of relocation implementation in conversation with the theory

101 of implementation analysis - although scarcely any in the context of post-disaster relocation. Rather,

102 researchers of development-induced displacement and resettlement (DIDR) have demonstrated the value

103 of a focus on implementation. Cernea (1997) noted the difficulty in keeping on-track with policy throughout

104 implementation and blamed both broad institutional capacities and dysfunctional relationships for

105 derailments. Rew et al. (2006) portrayed resettlement implementation as the "broad plateau" between policy

106 formation and implementation. "Away from the lofty hilltop of policy formulation, and rising from the 
107 damp lowlands of project implementation, there is the broad plateau of state departments with sectoral

108 responsibilities and the district towns within which [resettlement] and other policy lines are coordinated

109 and implemented" (Rew et al. 2006, pg. 51). In their analysis of displacement in both Uganda and India,

110 they highlighted the frequency of partial implementation or unsynchronized components (Rew et al. 2006).

111 This paper aims to follow the example of DIDR studies by applying implementation analysis specifically

112 to natural hazard-induced relocation. Furthermore, mass post-disaster relocation, largely executed by the

113 government, is most often a public infrastructure project. Prior literature has highlighted conflicts common

114 to public infrastructure projects, such as difference between government and public priorities or local versus

115 national processes (Min et al. 2018). A similar analysis of process, rather than only outcomes, has not been

116 applied to relocation. Conflicts may be exacerbated after a disaster, necessitating an in-depth look into how

117 conflicts and challenges evolve over the course of implementing relocation projects.

\section{Implementation of resilience}

119 Similarly, the study of relocation implementation can draw from parallels in the implementation of

120 resilience. Although reconstruction occurs during a reactive time period, it can be characterized as a

121 window-of-opportunity to proactively increase resilience (Birkmann et al. 2010). A wide-ranging and

122 abstract term, definitions of resilience have converged around the capacity to resist and adapt to multi-

123 system shocks (Opdyke et al. 2017; Ruszczyk 2019). Resilience discourse increasingly drives not only

124 academic inquiry, but also policy (Welsh 2014). As opposed to a traditional risk-oriented approach, which

125 focuses on known and quantifiable shocks, a resilience-oriented approach prepares integrated systems to

126 resist and recovery from emergent and highly uncertain threats (Trump et al. 2019). To mainstream

127 resilience, dedicated policies need to be incorporated across all government administrative levels, through

128 diverse sectors, and in collaboration with the private sector (OECD 2014).

129 Challenges to the implementation of resilience range from financial and technological to social and

130 organizational. In particular, the implementation of infrastructure resilience faces significant capital

131 investments, uncertain risk projections, improving limited organizational mandates, and the need to gather

132 and dissect comprehensive information, all while engaging the public (Azevedo de Almeida and Mostafavi 
133 2016). Not all organizations are equally equipped to implement resilience efforts (Jeong et al. 2018). For

134 instance, while national resilience initiatives are often assessed according to their competing costs and

135 benefits, similarly comprehensive cost-benefit analyses can be challenging at the community-level (Corotis

136 2018). Local governments may lack resources needed and it can be difficult to assign monetary value to

137 local-level benefits, such as quality-of-life and social capital (Aldrich 2012). Additionally, resilience

138 management requires cooperation among a multitude of relevant organizations, although their diversity can

139 impair inter-organizational cooperation (Naderpajouh et al. 2018). Achieving integrated and innovative

140 resilience-inspired projects has thus been hampered by mundane fiscal, technical, administrative, and social

141 hurdles. By focusing on relocation, which aims to increase the resiliency of communities, we can begin to

142 understand the nature of the hurdles prevalent in post-disaster resilience efforts.

\section{Case study context}

144 Although many countries, particularly those with a high risk of natural hazards, have pre-existing response 145 and recovery policies in place, it is common to craft unique, ad-hoc recovery policies endeavoring towards 146 ambitious goals for resiliency following major disasters (Sutley and Hamideh 2017). The creation of 147 disaster-specific policies occurred after Supertyphoon Haiyan struck the Philippines in 2013. Typhoon 148 Haiyan (locally named Yolanda) catalyzed a call for mass relocation of informal settlers out of coastal 149 zones. In the hardest-hit urban center, Tacloban City in the region of Eastern Visayas (i.e. Region VIII), the 150 households slated for relocation to the northern reaches of the city grew to over 16,000 . National, regional, 151 and local-level policies influenced relocation, but implementation over the last five years had 152 complications, particularly in regard to civil infrastructure systems. Although thousands of relocation 153 houses were built by June 2018, only 33 percent were occupied (CHCDO 2018), significantly stalled from

154 the 2016 deadline established during policy formation. With most house construction completed, other 155 aspects of relocation development impeded occupancy, further warranting an investigation into 156 implementation.

157 Opdyke et al. (2017) reviewed 25 years of infrastructure resilience literature; their review found 158 most followed a similar pattern (for instance, the majority were situated in North America). As a result, 
they identified areas where future research was needed, including diversity in context, scope, and

160 methodology of infrastructure resilience studies (Opdyke et al. 2017). The frequency of hazard events in

161 the Philippines positions the country to be a global leader in post-disaster approaches; accordingly,

162 analyzing differences between policy and implementation in the Philippines addresses a need to expand

163 resilience-oriented studies to non-North American contexts and atypical methodological lenses. To

164 demonstrate the multitude of organizations and their actions towards amending the discrepancies, water

165 supply was selected for a full investigation of how implementation evolved.

\section{Methodology}

167 Discrepancies - differences between policy and implementation - were identified in post-Haiyan Tacloban

168 City through classic content analysis. A second research phase dove into implementation analysis to 169 describe and explain processes more fully. To uncover and illustrate relocation implementation processes, 170 the research team primarily relied on fieldwork for this second phase.

\section{Defining policy and implementation in context}

172 Policy formation and implementation often overlap, but, in general, policy formation occurs earlier

173 and is more distinct (Hill and Hupe 2014). Broadly defining policy formation in time and scope would

174 result in no discrepancies; while severely constricting the definition of policy formation would leave the

175 impression that nearly everything is a discrepancy - discrediting good work done by decision makers in the

176 early policy stage. The line between policy formation and implementation is blurry and highly context

177 dependent (Schwab 2014). Depending on various pre-existing conditions and the severity of the disaster,

178 outlining recovery can take months to years (Schwab 2014). For instance, Iuchi (2014) found some

179 communities required more than a year to develop relocation plans following an earthquake in Japan in

180 2004. At the same time, there is pressure to begin recovery projects quickly. Similar to previous disasters,

181 construction of permanent houses, an indicator that implementation was initiating, began within a year of

182 the disaster (Ganapati and Ganapati 2008).

183 Seeking a reasonable balance, this research defined policy formation to the year following the 184 disaster (November 2013 through November 2014) and limited scope to only official and relocation- 
185 relevant documents published by Tacloban City or its direct administrative hierarchy. Constraining the 186 window to November 2013 through November 2014 excluded pre-existing overarching policies, such as 187 the Philippine Disaster Risk Reduction and Management Act of 2010, but included Haiyan-specific 188 presidential orders and national agency-sanctioned recovery policies. Including pre-storm recovery policies 189 would have shifted the analysis away from distinct Haiyan policies towards broad expectations. In 190 comparison, post-storm documents provided a relevant picture of what was considered and prioritized 191 during Haiyan policy formation. Official documents are those endorsed by government committees and/or 192 agencies at each administrative level, such as the City Mayor's Office (local), Regional Development 193 Council (regional), or the Office of the Presidential Assistant for Rehabilitation and Recovery (national). 194 In all, five national, one regional, and one local document were identified as post-disaster, relevant, 195 and official (see Table 1). The local and regional documents are "the" recovery policy documents at each 196 level. The city-level policy grew out of a new inter-departmental task force responsible for local-level 197 Haiyan recovery and relocation policies (Blanco 2015). Tacloban City was the first to submit their local 198 plan to the national government, which set 2016 as the deadline for relocation houses and support facilities 199 in "Tacloban North" (Tacloban City 2014). There was a concerted effort to up-channel local-level policies 200 so they could be meaningfully incorporated into national objectives and funding. Their parallel at the 201 national-level, the Yolanda Comprehensive Rehabilitation and Recovery Plan, was included along with 202 four other national-level documents providing additional funding, contracting, and regulatory information 203 pertinent to relocation.

204 In comparison, implementation was set to the five-year period after the event (November 2013 205 through November 2018). Policy documents defined two to three years as the implementation timeframe 206 for relocation, but fieldwork visits to relocation sites in 2016, nearly three years after the typhoon, revealed 207 implementation was ongoing. Observed delays necessitated an expansion to five years, a point at which 208 as the forthcoming discussion of discrepancies illustrates - researchers witnessed signs that major 209 implementation struggles were resolving. To eliminate overlap of implementation with policy documents, 210 only official documents from December 2014 to November 2018 were considered (see Table 2). 
212 policy responses, documents in the following years mostly came out of routine agency practices. To

213 systematize document identification, the search was grounded in publicly available products of the Regional

214 Development Council (RDC). The council's stamp of approval - given as a 'resolution' in support of

215 particular decision - is instrumental in elevating a claimant's petition to national-level offices. RDC

216 resolutions are intrinsically corrective, meant to call attention to operational problems, especially those

217 issues struggling to proceed smoothly or garner necessary attention in other government bodies. All 262

218 posted regional resolutions between December 2014-November 2018 were reviewed for relevance. Only

219 those specifically addressing relocation in Tacloban City and pertaining to the general relocation effort

220 (rather than single-site issue) were considered. Furthermore, some resolutions simply stated the council's

221 approval of other relocation implementation documents. In these cases, the resolution was replaced by the

222 original document. This process identified two national and one local-level implementation document as

223 well as six relevant RDC resolutions.

\section{Classic content analysis}

225 Classic content analysis, wherein the researcher counts the frequency of thematic codes, relies on

226 an explicit set of replicable procedures to systematically classify data, reduce complexity, and produce valid

227 inferences (Bauer 2000; Leech et al. 2011). It is well-suited for analyzing document-type data to answer

228 comparative research questions (Leech et al. 2007; Onwuegbuzie et al. 2012). The set of procedures for this

229 study began with the rationale for document selection and continued with the identification of relocation-

230 relevant sections. All documents were imported into the qualitative coding software NVivo and organized

231 according to 'policy formation' (Table 1) or 'implementation' (Table 2) classifications. We used systematic

232 coding procedures within NVivo to aid the analysis. Next, because national and regional-level documents

233 were not singularly focused on Tacloban City relocation, relevant sections to include in the analysis were

234 identified (i.e. specifically regarding relocation). Qualitative codes emerged around the documents'

235 descriptions of the intended observable outputs, such as youth programs or electrical supply. Content

236 analysis was performed using NVivo's matrix coding function, which compares code frequency between 
237 classifications. The number of times an output was coded per classification, policy or implementation, was

238 telling - imbalance suggests potential discrepancies. To identify the most extreme discrepancies, researcher

239 case knowledge informed pattern identification (Flyvbjerg 2006).

$240 \quad$ Fieldwork

241 Analysis of discrepancy evolution was an iterative process involving extensive fieldwork throughout

242 implementation. Researchers conducted nine months of fieldwork over three trips from June 2016 to

243 November 2018. To gain a comprehensive awareness of water supply implementation, data sources were

244 broadened in scope (including unofficial sources) and time (extending back through the first year to

245 November 2013). The review of implementation documents was expanded to include both official and

246 unofficial documents such as: agency-provided planning factors, progress updates, monitoring data, inter-

247 agency correspondence, and presentations. The research team longitudinally observed construction across

248 all of Tacloban City's relocation project sites, attended numerous planning and monitoring meetings, and

249 interviewed 43 decision makers across national, regional, and local bodies as well as representatives from

250 non-governmental and community advocacy organizations (Table S1). Six participants interviewed in 2016

251 provided follow-up interviews in 2017 and/or 2018, for a total of 51 interviews conducted in all.

252 Implementation analysts view in-depth interviews with, and observations of, decision makers

253 critical for gaining a processual understanding of implementation (Schofield 2001). Questions to officials

254 at the local water district, national water administration, and other concerned organizations targeted

255 implementation of the permanent water supply, such as "What do you see as the cause of the development

256 delay? Can you walk us through the technical specifics?" Follow-up interviews over three years allowed

257 longitudinal insight into shifting implementation issues. For example, following a major Supreme Court

258 decision, new questions inquired "how did the recent ruling regarding water-board leadership affect your

259 relationship with the local water district? How might it affect project development?" Additional semi-

260 structured interview questions can be found in Supplemental Table S2. 
262 Interviews were transcribed and imported into NVivo, then qualitatively coded for water supply. To add 263 depth to the case study (Gibbert et al. 2008), a mixed-methods approach combined process action mapping 264 and narrative analysis to elaborate on how the added discrepancy of water supply was surfaced and 265 addressed. Process mapping organized key implementation events chronologically while narrative analysis 266 filled in events with a richer understanding of who was involved and how they progressed implementation.

267 Process mapping complements narrative analysis, and vice versa. Process maps punctuate the narrative with 268 time-stamped events in chronological order, providing a parsimonious picture of implementation. Narrative 269 analysis adds context and characters, allowing the process map to be viewed from the perspective of various 270 actors involved in implementation.

271 Process mapping is the visualization of decision and actions into a simplified chronological and 272 causal flowchart. The goal of mapping was to identify, organize, and highlight key implementation 273 milestones. All relevant observational notes, documents, and interview data were reviewed to build maps 274 to chart the trajectory of decisions and actions. Process mapping has been shown to be a useful tool for 275 investigating decisions in engineering and the built environment (Bouchart et al. 2002). Events are time 276 stamped in cases where the date is confirmed through either an official document or two-or-more 277 interviewees. Existing literature emphasizes the copious number of variables influencing policy 278 implementation (Brynard 2009). To create a defendable map, decision points were limited to factors and 279 events deemed pivotal by interviewees and supported by documentation.

280 Next, the process maps were supplemented with interviewees' narrative accounts of 281 implementation. The decisions and actions that unfolded throughout implementation are messy, 282 interwoven, and difficult to abbreviate. Multiple perspectives are shared to complement each other and 283 make sense of uncertainties and complexities (Roe 1994). In constructing a synthesized narrative of 284 implementation, all perspectives were considered to be "equally valid elements" of the larger 285 implementation process in order to fairly depict complexity (Hukkinen et al. 1990, pg. 312). 
Narratives, common in case studies, employ literary tools such as setting, plot, and character to 287 explain policy phenomena (Flyvbjerg 2006; Jones and McBeth 2010). Here, the setting is not 288 geographically discrete. Although the policy concerns what happens in a specific geographic area (Tacloban

289 North), the storyline plays out across geographic and institutional venues; in the boardrooms of national

290 offices, at the mayor's desk, and in community spaces. The narrative depicts a cast of organizations as key 291 characters, but decline to portray any one person, agency, or group as a definitive hero, villain, or victim.

292 There is a strong tradition of narrative analysis in disaster recovery and resilience research, but largely (and 293 importantly) from the perspective of affected communities, such as Chamlee-Wright and Storr's (2011)

294 account of collective narratives of resiliency in a Louisiana parish post-Katrina. Less abundant are 295 narratives through the lens of implementors (Drennan 2018), those with the access and agency needed to 296 create realistic and actionable recommendations for improved relocation policy formation in the future.

\section{Results}

298 Two types of discrepancies were uncovered. "Unfulfilled" discrepancies are items covered in policy 299 documents but not present in implementation. Conversely, "added" discrepancies emerged where policy

300 under-addressed an issue and it was "added" during implementation by necessity. The implementation of 301 added discrepancy, water supply, was investigated in depth and expanded on via a narrative and process 302 mapping.

\section{Identified Discrepancies}

304 Table 3 depicts results of the classical content analysis where each instance of a discrepancy is counted. In 305 the final column, the number of implementation references was subtracted from policy references, therefore 306 added discrepancies appear as less than zero and unfulfilled discrepancies as greater. 41 codes emerged 307 during qualitative coding. To help uncover patterns, codes were thematically grouped into six categories: 308 beneficiary readiness ( 1 code), community services ( 9 codes), housing ( 5 codes), infrastructure (13 codes), 309 planning and land management (4 codes), and vulnerable populations (9 codes). The grouping helped to 310 identify trends among related codes and across different broader themes. 
311 There were only unfulfilled discrepancies for all beneficiary readiness, housing, or planning and land

312 management codes. The vulnerable populations code gender was coded ten more times in policy 313 documents, making it the largest unfulfilled discrepancy. This was followed by the community services

314 code livelihoods (coded 8 more times in policy documents). All codes grouped under planning and land 315 management (land development (7 more), acquisition and titling (6), permitting (5), and environmental 316 protection (4)) depicted considerable unfulfilled discrepancies.

317 More than one explanation could account for unfulfilled discrepancies, those issues addressed as 318 important in policy but largely void from implementation documents. Negatively, it is possible the issue in 319 question was palatable policy rhetoric but later forgotten or unactionable. Positively, since the suite of 320 implementation documents can be corrective, it is possible decision makers felt such considerations were 321 well-addressed, and thus did not need to be featured. It is likely the drivers of each unfulfilled discrepancy 322 are slightly different. Below, plausible causes are explored based on case knowledge.

323 For some issues, like land acquisition and titling, the window of relevance may happen too quickly.

324 Policy emphasized the need to improve land acquisition procedures, but there was little evidence that 325 eminent domain was systematically overhauled for relocation socialized housing. A review by the country's 326 internal audit agency found implementors struggled to identify and procure topographically suitable and 327 legally viable sites efficiently (COA 2018). It is also possible the implementation time frame of five years 328 is too short to capture the full nature of land acquisition; titling issues will likely be confronted in the future. 329 Other issues are initially hard to see and therefore hard to enforce, monitor, or correct. Land 330 development problems, like negative drainage or poor compaction of soil under houses, are difficult for 331 non-engineers to assess and unlikely to be corrected post-construction. Similarly, environmental 332 degradation is masked until the population swells and damage is amplified. Even once the need is visible, 333 however, environmental protection remains difficult to implement due to competing goals, for instance 334 between development of accessible community facilities, like markets and schools, and conservation of 335 ecologically sensitive areas such as wetlands. 

surprised, as interviews with both decision makers and visits with community members revealed accessible and reliable livelihood opportunities were top priorities. The reality is that relocated families are struggling financially (Tuhkanen et al. 2018). The absence of livelihood in implementation documents is due to a lack of livelihood interventions that adequately stimulated sustainable incomes for relocated households and suggests ambiguity on how to move forward.

It is also possible some unfulfilled discrepancies were permanently abandoned. Policy highlighted goals to address entrenched socioeconomic conditions. However, the societal root causes of vulnerability

344 are fortified by power imbalances and difficult to truly affect (Gaillard et al. 2007). Traditionally, the field

345 of development, not disaster response, has worked to address root drivers of inequality and, by extension,

346 vulnerability. Some among the international community of humanitarian disaster responders have lobbied

347 to purposefully bridge response into development (Sanderson 2017; Schipper and Pelling 2006). In the case

348 of Haiyan relocation, it is promising policy sought to address embedded institutional and socioeconomic

349 causes, but such deep-rooted issues were unaddressed in actuality.

In comparison, "added" discrepancies were issues overlooked in relocation policy formation. For

351 example, where policy documentation mentioned school development, the discussion is void of details for 352 operational responsibility throughout implementation. The four references coded under schools within 353 policy classified documents tended to be vague: "The resettlement sites shall be provided with basic 354 community facilities such as multi-purpose covered courts and school buildings" (OPARR 2014, pg. 49).

355 In comparison, there were ten references in implementation, several commenting on the unaddressed need 356 to construct schools: "The absence of classroom and learning spaces impedes the relocation of affected 357 families” (RDC VIII 2015, pg. 1).

The infrastructure code water supply stood out among all added discrepancies (coded 18 more times

359 in implementation documents compared to policy), followed by schools (6 more), local police (5), roadways

360 to relocation sites (versus internal site roads) (4), and daycare (4). Added discrepancies were dominant in

361 infrastructure and community service codes; four out of thirteen infrastructure codes and four out of nine 
362 community service codes had two or more references in implementation than policy. Thus, added

363 discrepancies shared a common thread: they occurred in the cross-project services needed to tie relocation

364 sites together as a cohesive community.

\section{Narrative of relocation water supply implementation}

366 The implementation of water supply to relocation houses can be characterized by a lack of clarity regarding 367 organizational roles and responsibilities, disjointed transitions between temporary and permanent solutions, 368 the bundling of infrastructure into a larger recovery plan and funding package, and a need to improve project 369 management procedures. The narrative serves as an in-depth example of how engineering management was 370 critical to the implementation of post-disaster resiliency efforts. Implementation unfolded in two parts.

371 First, how waterless sites were selected for relocation development and, second, the course correction 372 towards a permanent water supply.

\section{Site selection}

374 The local-level policy document, the Tacloban Recovery and Rehabilitation Plan, identified water 375 supply to relocation sites as a key infrastructure precondition for sustainable development in the northern 376 area (Tacloban City 2014). However, new system development was not carried into the regional-level 377 document or specified in its attached projected expenditure breakdown. The overarching national 378 document, written by a specially-appointed recovery commission, only went so far as to note in-site water 379 reticulation as a part of site development (OPARR 2014). Such cursory descriptions of relocation services 380 in policy products suggest service provision was presumed throughout policy formation. Looking back, a 381 national official acknowledged "the program then was just housing construction, the assumption was that 382 the National Housing Authority will provide the water connections and power connections within the 383 resettlement site but the assumption is the local water provider would be able to provide water" (2016, 384 emphasis ours).

385 Well-defined water supply requirements did not make it into the most detailed government-housing 386 document of the policy phase; the terms of reference under the National Housing Authority's Yolanda 387 (Haiyan) permanent housing program. The terms of reference only stipulated "the water distribution system 
shall be in place and ready to accept supply from any available water source" -without a requirement to first check for accessible and reliable water sources in site evaluation. The terms did request "plans, agreements, and all other documents pertinent to power and water supply" as a part of submissions but noted the requirement could be temporarily waived. Even worse, the terms incentivized contractors to select

392 service-poor areas. The terms favored large developments, up to a maximum of 1000 houses, pushing 393 developers towards larger tracts of distant farmland rather than smaller plots in peri-urban areas with 394 existing water service. The terms of reference also stipulated a fixed payment per house regardless of the 395 cost of land acquisition. Savvy contractors increased their profit margin by purchasing the cheapest land396 in general, land that was unincorporated into utility services, far from schools, disconnected from economic 397 centers, and, in some cases, in a floodplain.

Arguably, the decision is owned by multiple stakeholders: the contractors who identified and proposed the site, as well as the National Housing Authority (NHA) and city council who approved the proposal. Water authorities did not play an active role in site selection. Both the NHA and the city 401 government technically had the power to redirect site selection towards water accessibility. However, both 402 were also under extreme pressure to make fast progress, a well-known post-disaster phenomenon 403 (Olshansky et al. 2012). In the NHA, pressure manifested in the agency's leveraging of negotiated 404 procurement, a nonstandard process intended only for times of urgent need. Negotiated procurement 405 enabled the government to respond quickly; thus, the NHA entered rapid conversations with general 406 contractors and fast-tracked awards. However, negotiated procurement limits competition, making it, at 407 best, a weak tool in identifying qualified contractors and, at worst, highly vulnerable to corruption or 408 mismanagement (Jones 2009). Overall, the nature of relocation housing procurement incentivized rapid 409 acquisition over accessible service provision. This is depicted in Figure 1, as the process map begins with 410 the construction of relocation sites and is not preceded by intentional planning of water supply.

411 At the local level, city leadership had envisioned growth in the northern area for years, despite 412 anticipated difficulty in servicing the area with water infrastructure due to decades-old political tensions 413 between the city and provincial water district (the Leyte Metropolitan Water District; LMWD): "the 
414 discussion about LMWD is way, way beyond the technical discussion" (City official; 2016). Likewise,

415 there was political tension between the city and national executive leadership, each ran by patriarchs of

416 prominent political families. Interviewees at each level of governance confessed a lack of trust in their

417 hierarchical counterparts, contributing to tensions and delayed progress.

418 Course correction for water supply

419 As both government and non-government housing progressed, households began to transfer into

420 relocation sites in 2014. Water supply was segmented into potable and domestic trucked delivery. The

421 expanding population stressed service delivery to its capacity (noted in the top left corner of the process

422 map, Figure 1). In late 2014 and into 2015, a USAID program explored new avenues of bulk water supply

423 for Tacloban North, specifically new source development via a public-private partnership. The study

424 culminated in a feasibility report for the city (USAID 2015). In March of 2015, the water organizations

425 were invited for the first time to a meeting regarding Tacloban City's relocation sites (as attested by

426 representatives at both the national agency and provincial utility, Leyte Metropolitan Water District

427 (LMWD)). Throughout 2015, while the existing water supply system approached its limit and transfer had

428 to be halted, the city, NHA, LMWD, and national water agency began to coordinate.

429 By December 2015, a resolution of the Regional Development Council entreated the national 430 agency to fund water infrastructure development for relocation sites and garnered an invitation to present 431 the proposal at the national level. In May of 2016, water supply was packaged with the full suite of projected 432 relocation programs in the Tacloban North Integrated Development Plan and subsequently endorsed by the 433 Regional Development Council. The city and provincial water utility then shared their vision for a three434 phased water supply expansion project ((1) trucked delivery, (2) local reservoirs, and (3) piped permanent 435 infrastructure) to an audience with the national offices of NEDA, the Local Water Utilities Administration, 436 and the Department of Budget and Management in July of 2016. Delegates from the city and water district 437 were nervous entering the meeting - if the proposal was rejected, it felt likely that the entire relocation 438 endeavor (and their vision for a thriving relocation community) could fail as well. City officials knew 439 pursuing partnerships with private providers was an option, but, for them, unchartered territory and an 
uncertain back-up plan. Unexpectedly, they found the national actors agreeable to the plan (depicted as the

441 July 2016 "national endorsement" decision point in Figure 1) and funds were conditionally committed

442 pending a full technical evaluation. The national water agency, the Local Water Utilities Administration

443 (LWUA), agreed to send technical advisors to Tacloban City to assess feasibility. Several local officials

444 opined the national government was accommodating because the newly-elected president was politically

445 aligned with city leadership.

446 After the July 2016 national meeting, water supply felt forthcoming. In October 2016, after design

447 adjustments following the technical evaluation, a project engineer with LWUA stated they were finalizing

448 plans for the permanent supply. He expected to bid it out as a design-build project shortly and anticipated

449 construction would begin January 2017. Conservatively estimating construction could take as long as two

450 years, the engineer projected water would flow to relocation homes by January of 2019.

451 Instead, progress stalled while organizational crisis erupted at the provincial level. In December

452 2016, the Supreme Court ruled on a case of a different city with similar political tensions between the city

453 government and provincial water utility provider (Rama v. Moises 2016). The court ruling upended the

454 legitimacy of the provincially-appointed board of directors and ignited frontpage inter-agency conflict

455 (Gabieta 2017). Meanwhile, employees and community members stated they felt caught in the middle.

456 Project communication became irregular and interviewees described a lack of awareness on the progress of

457 project partners. The disruption highlighted the vulnerability of the management of post-disaster 458 engineering projects to broader organizational and political dramas. By the time a state of normalcy 459 returned - with the city newly in command of the water district - progress on the expansion project for 460 relocation areas had to be reinvigorated.

461 It required another year, throughout the remainder of 2017 and most of 2018, for the national and

462 local water utility to draft a unified conceptual design and determine water supply performance

463 requirements before advertising the design-build project for bid. The conceptual design includes new source

464 development, both rehabilitated and new reservoirs and pump stations, and distribution pipes to more than

465 a dozen relocation site hubs. Additionally, it includes a proposed intake and reverse osmosis treatment 
system in the northern area. The reverse osmosis system is intended as a back-up to seasonally augment

467 primary distribution (LWUA 2018).

468 The bid was initially presented by the national-level agency, but unsuccessfully. The water district 469 argued they could handle managing the project and were transferred the funds and delegated authority. By

470 December 2018, the project was awarded as a joint venture to two developers for just under $\$ 10$ million

471 USD. The depicted process map (Figure 1) thus ends with 2019, and the start of system construction.

472 Additionally, 2018 saw programmatic changes, as the NHA's terms of reference were updated to remove

473 their own culpability in sourcing water at future relocation sites: "The plans and the installation of the water

474 distribution system shall be approved and supervised by the Local Water District and the NHA to ensure

475 the connection of the system to available water main/source... The LGU and Local Water Districts shall

476 provide the tapping from the water source. Otherwise, the Contractor-Developer must provide its own water

477 system" (NHA 2018).

478 Throughout the implementation of water supply infrastructure, decisions in each phase of 479 implementation propagated to the next. First, policy documents did not specify ownership over water supply 480 to relocation sites and inadvertently incentivized the selection of relocation land outside of existing water 481 service. Transferred households relied on a mix of well-water, truck-to-tank delivery, and private providers. 482 As it became increasingly obvious that short-term water solutions would not be adequate, the city 483 government found they had to re-package relocation requirements and form new relationships, especially 484 with the local water district, to convince national agencies to fund the project. Once funds were 485 conditionally secured, disjointed project management delayed tangible progress for years before the (now 486 city-run) water district selected a joint venture to implement the design-build phase.

\section{Discussion}

488 Several elements of the implementation of relocation-specific water supply infrastructure resonated with 489 core implementation literature. For instance, Bowen noted implementation occurs in "open systems" 490 subject to shake-ups such as shifting political allegiances, unexpected resignations, or fluctuating priorities 491 (1982). Interviewees felt the effect of their open system - they commented on national elections and court 
492 decisions both positively and negatively affecting their work and the timeline of implementation. In contrast

493 to the conceptualization of implementation as a series of independent step-wise approvals, Bowen also

494 identified catalyzing processes, such as “packaging”, i.e. bundling multiple requests into one appeal (1982).

495 City officials leveraged packaging when presenting their integrated plan for relocation to the regional-level

496 and they worked with the water district to package their request for three-phased water supply funding into

497 a single approval at the national-level. Given that post-disaster engineering projects can be marred by

498 accusations of slow progress, the identification of efficiency-improving tactics such as packaging is of

499 critical concern.

500 Implementation research questions whether national or local-level project ownership enhances

501 successful implementation, with evidence pointing towards centralization as national actors may be more

502 aligned with policy intent (Hupe 2011). However, the discrepancy of water supply emerged in part because

503 policy lacked goal clarity and did not detail particular ownership of relocation projects, allowing for varied

504 interpretations of policy intent. Policy documents failed to require readily available water at relocation sites

505 and overlooked who would be responsible to pay for identifying, constructing, and maintaining the

506 connection to source water. This was followed by the local-level assertion that local leadership is best fit to

507 implement the project, if only funding would be transferred.

508 The narrative also resonated with aspects of the implementation of resilience, such as the

509 importance of social trust or the value of redundant systems. Naderpajouh et al. (2018) note mutual trust is

510 an enabler of resilience management, but, as interviewees reported, the relocation implementation was

511 hindered by some suspicions of political bias and limited trust between various government offices and

512 levels. Furthermore, although deliberate resilience-oriented improvements did not appear to influence the

513 system design, interim implementation solutions did lead to a potential layer of redundancy that may

514 enhance overall resilience of the water supply. Relocation water delivery imitated a dual water distribution

515 system, wherein potable and non-potable water are treated and distributed separately to decrease overall

516 energy and operating costs (Rasoulkhani et al. 2019). In the case of Tacloban City the separation was driven

517 by expense and last-mile delivery capacity; there simply were not enough trucks and tanks to unify domestic 
518 and potable water needs into a single distribution system. Positively, if the local government retains 519 ownership of trucks after the piped system is constructed, having them in reserve adds a layer of redundancy 520 for area water supply. This layer of redundancy, combined with the potential of the nearby reverse osmosis 521 system, contribute to the overall resilience of the water supply.

522 Implementation included interim solutions to be followed by permanent infrastructure, i.e. piped 523 municipal water. By design, temporary infrastructure services are incapable of meeting long-term standards 524 of quality and capacity. Transitional services are common in post-disaster relocation, the development of 525 other relocation services, including housing and schools, also included elements of temporality. The 526 transition between temporary and permanent housing, or lack thereof, is somewhat contentious among 527 humanitarians and was a point of discussion in Tacloban City following Typhoon Haiyan. Some contend 528 relief organizations are not responsible for full community recovery and should not attempt to provide 529 permanent solutions, while others acknowledge housing projects intended to be transitional often become 530 permanent (Opdyke et al. 2018). An insistence that temporary housing is short-term encourages rapid 531 transition into permanent relocation communities before support infrastructure is implemented. The irony 532 is that while families have escaped temporary housing, they may be permanently stuck with temporary 533 infrastructure services.

534 An interminable time for temporary solutions is due, in part, to protracted design and contracting. 535 More than two years passed between when the national government agreed to commit funds and the project 536 was awarded. Literature suggests project delays are primarily due to inadequate management practices such 537 as poor project control or coordination (AlSehaimi et al. 2013). Management-related delays applied to 538 Tacloban City relocation; interviewees felt the combined engineering ability of government was sufficient 539 for crafting conceptual designs, but the capacity to solicit funds, manage rounds of multi-stakeholder design 540 reviews, and efficiently award contracts was lacking. Despite significant literature into the optimization of 541 resource allocation during post-disaster construction of infrastructure systems (Orabi et al. 2010), 542 optimization of internal project management personnel and resources was lacking. To successfully engineer 543 relocation infrastructure, increased project management training and capacity appear to be needed not only 
544 within the national housing agency, but within all agencies that will need to contribute resources, such as

545 the national and local water authorities.

546 Government water agencies elected to develop the conceptual design and performance metrics, but

547 contract out final design and construction to a single entity. Overstressed government agencies sought to

548 lessen their workload, but literature shows design-build arrangements can be more administratively

549 burdensome, especially in the early stages (Molenaar et al. 1999). Multi-year delays throughout

550 implementation underscore a need to further investigate the benefits (or drawbacks) of design-build contract

551 types in new infrastructure construction in post-disaster environments, especially in low- and middle-

552 income countries where government project management processes may still be maturing.

553 Finally, existing literature has highlighted the need for increased construction oversight throughout

554 recovery to minimize mistakes and increase efficiency, both in terms of quantity (time on site) and quality

555 (inspections by engineers or technically-trained staff) (Jordan et al. 2016). Although outcomes were not

556 evaluated in this paper, emerging discussions of limited oversight and poor relocation housing quality

557 presented by other Haiyan researchers suggests it is reasonable to expect insufficient construction oversight

558 for water supply construction (Arroyo and Åstrand 2019). It was not evident that agencies modified

559 personnel assignments or funded new positions specifically responsible for oversight of relocation water

560 supply. If oversight is minimal, the resulting poor quality may affect both the immediate and long-term

561 functionality of water distribution.

\section{Conclusion}

563 To identify discrepancies, the degrees to which both policy and implementation addressed outputs (i.e.

564 observable relocation services and infrastructure) were cataloged and compared. Next, the implementation

565 of one consequential and well-documented discrepancy - water supply - was explored via a cohesive

566 narrative account and process map, together illuminating the timeline of significant steps, key players, and

567 overall processes.

568 In the investigation of discrepancies between policy and implementation, added discrepancies

569 (those not addressed well in policy but rather during implementation) tended to be cross-project 
570 infrastructure services, such as water supply, schools, and electricity, while unfulfilled differences (present

571 in policy documents, but not evident in implementation) were programs aimed at root-cause issues, such as

572 gender inequality, poverty, and tenure security. Although not purposefully or maliciously unfulfilled, many

573 important social programs were derailed during implementation to the determent of deeper development-

574 related concerns. Both unfulfilled and added discrepancies point to considerable funding issues. Aligning

575 policy and implementation will likely require additional funding, either to maintain momentum for social

576 programs so they do not become unfulfilled discrepancies or to build in line items for all required

577 infrastructure services so they do not emerge as added discrepancies.

578 Relocation policy did not anticipate the difficulty of implementing non-housing infrastructure and services.

579 Civil infrastructure services were prominent added discrepancies, indicating they were ill-conceived in 580 policy, leaving them open to interpretation and confused ownership throughout implementation. Key 581 infrastructure services, such as water supply and schools, were not outlined as metrics for project 582 completion nor provided for in recovery funding. The narrative of water supply implementation suggests 583 added discrepancies initially lack clear ownership, unfold in phases, and can experience significant delays, 584 despite attempts quicken development by packaging water supply with other relocation priorities. The 585 government attempted to streamlined implementation through negotiated procurement contracts and 586 design-build arrangements for civil infrastructure, but it is not clear that either successfully quickened the 587 process. Rather, at the time of writing, water supply is under-construction and households are relying on 588 trucked-delivery as an interim solution while awaiting permanent, piped service. If construction completes 589 as planned and water supply is provided without issue, the city may retain water trucks for future use, thus 590 improving their resiliency by gaining a layer of redundancy. However, if delays or construction quality 591 problems occur, households may have to rely on intended-to-be-temporary infrastructure services for the 592 long-term.

593 Moving forward, policy documents should reiterate responsibilities and eliminate assumptions 594 explicit explanations of goals, ownership, and processes can alleviate initial confusion and tension - and 595 match each program or infrastructure service with a dedicated line item in recovery funding. Many of the 
596 organizations attempting to address water supply were not present during post-typhoon recovery and 597 relocation policy formation. During implementation, peripheral government agencies (not only emergency 598 or housing organizations) would benefit from additional project management training in order to integrate 599 into implementation processes more smoothly. This study provided one of the first in-depth looks into 600 implementation of a critical element of relocation. As researchers gain familiarity with the nuances of 601 relocation, future research may compare how relocation is implemented across contexts and following 602 different hazard events. The implementation of relocation may serve as a microcosm for the implementation 603 of resilience more broadly, and future research should continue to investigate parallels. 


\section{Data Availability Statement}

605 Some data used during the study were provided by a third party: All documents noted as "official" 606 government documents and used in the classic content analysis. Direct requests for these materials may be

607 made to the appropriate government agencies or accessed online.

608 Some data generated or used during the study are proprietary or confidential in nature and may only be 609 provided with restrictions (e.g. anonymized data): Interviewee data and interview transcripts.

\section{Supplemental Data}

611 Tables S1 and S2 are available online in the ASCE library (ascelibrary.org).

\section{Acknowledgements}

613 This material is based upon work supported by the National Science Foundation under Grant No. 1434791

614 and Grant No. 1650115, and the United States Agency for International Development Office for Foreign

615 Disaster Assistance and Habitat for Humanity International 2017 Shelter and Settlements Fellowship. Any

616 opinions, findings, and conclusions or recommendations expressed in this material are those of the authors

617 and do not necessarily reflect the views of the funding agencies. 


\section{References}

Aldrich, D. P. (2012). Building resilience: Social capital in post-disaster recovery. University of Chicago Press.

AlSehaimi, A., Johnson, L., and Tzortzopoulos, P. (2013). "Need for Alternative Research Approaches in Construction Management: Case of Delay Studies." Journal of Management in Engineering, 29(4), 407-413.

Arroyo, I., and Åstrand, J. (2019). "User involvement in housing recovery after typhoon Haiyan from a capability perspective." International Journal of Disaster Risk Reduction, 38, 101158.

Azevedo de Almeida, B., and Mostafavi, A. (2016). "Resilience of Infrastructure Systems to Sea-Level Rise in Coastal Areas: Impacts, Adaptation Measures, and Implementation Challenges." Sustainability, 8(11), 1115.

Bauer, M. W. (2000). "Classical content analysis: A review." Qualitative researching with text, image and sound, 131-151.

Bavinck, M., Klerk, L. de, Plaat, F. van der, Ravesteijn, J., Angel, D., Arendsen, H., Dijk, T. van, Hoog, I. de, Koolwijk, A. van, Tuijtel, S., and Zuurendonk, B. (2015). "Post-tsunami relocation of fisher settlements in South Asia: evidence from the Coromandel Coast, India." Disasters, 39(3), 592609.

Birkmann, J., Buckle, P., Jaeger, J., Pelling, M., Setiadi, N., Garschagen, M., Fernando, N., and Kropp, J. (2010). "Extreme events and disasters: a window of opportunity for change? Analysis of organizational, institutional and political changes, formal and informal responses after megadisasters." Natural Hazards, 55(3), 637-655.

Blakely, E. J., and Fisher, P. M. J. (2017). "Assessing non-metro recovery across two continents: issues and limitations." Disasters, 41(3), 487-504.

Blanco, D. V. (2015). "Disaster Governance in the Philippines: Issues, Lessons Learned, and Future Directions in the Post-Yolanda Super Typhoon Aftermath." International Journal of Public Administration, 38(10), 743-756.

Bouchart, F. J.-C., Blackwood, D. J., and Jowitt, P. W. (2002). "Decision mapping: Understanding decision making processes." Civil Engineering and Environmental Systems, 19(3), 187-207.

Bowen, E. R. (1982). "The Pressman-Wildavsky Paradox: Four Addenda or Why Models Based on Probability Theory Can Predict Implementation Success and Suggest Useful Tactical Advice for Implementers." Journal of Public Policy, 2(1), 1-21.

Bozeman, B. (2013). "What Organization Theorists and Public Policy Researchers Can Learn from One Another: Publicness Theory as a Case-in-Point." Organization Studies, 34(2), 169-188.

Brynard, P. A. (2009). "Mapping the factors that influence policy implementation."

Cannon, T. (1994). "Vulnerability Analysis and the Explanation of 'Natural' Disasters." Disasters, Development and Environment, John Wiley \& Sons Ltd, 13-30.

Cernea, M. (1997). “The Risks and Reconstruction Model for Displaced Populations." World Development, 25(10), 1569-1587.

Chamlee-Wright, E., and Storr, V. H. (2011). "Social Capital as Collective Narratives and Post-Disaster Community Recovery." The Sociological Review, 59(2), 266-282.

CHCDO. (2018). "No. of Families in the North as of June, 2018." Tacloban City Housing and Community Development Office.

COA. (2018). Annual Audit Report on the National Housing Authority For the Years Ended December 31, 2017 and 2016. Commission on Audit.

Corotis, R. B. (2018). "Planning for Community Resilience Under Climate Uncertainty." Climate Change and Its Impacts: Risks and Inequalities, Climate Change Management, C. Murphy, P. Gardoni, and R. McKim, eds., Springer International Publishing, Cham, 145-159.

Doberstein, B., and Stager, H. (2013). "Towards guidelines for post-disaster vulnerability reduction in informal settlements.” Disasters, 37(1), 28-47. 
Drennan, L. (2018). "FEMA's fall and redemption—applied narrative analysis." Disaster Prevention and Management: An International Journal, 27(4), 393-406.

Flyvbjerg, B. (2006). "Five Misunderstandings About Case-Study Research." Qualitative Inquiry, 12(2), 219-245.

Gabieta, J. A. (2017). "Reforms in water supplier sought." Inquirer.Net, $<$ https://newsinfo.inquirer.net/949536/reforms-in-water-supplier-sought $>$ (Jul. 17, 2019).

Gaillard, J.-C., Liamzon, C. C., and Villanueva, J. D. (2007). "Natural' disaster? A retrospect into the causes of the late-2004 typhoon disaster in Eastern Luzon, Philippines." Environmental Hazards, 7(4), 257-270.

Ganapati, N. E., and Ganapati, S. (2008). "Enabling Participatory Planning After Disasters: A Case Study of the World Bank's Housing Reconstruction in Turkey." Journal of the American Planning Association, 75(1), 41-59.

Gibbert, M., Ruigrok, W., and Wicki, B. (2008). "What passes as a rigorous case study?" Strategic Management Journal, 29(13), 1465-1474.

Hill, M., and Hupe, P. (2006). "Analysing policy processes as multiple governance: accountability in social policy." Policy \& Politics, 34(3), 557-573.

Hill, M., and Hupe, P. (2014). Implementing public policy: An introduction to the study of operational governance. Sage.

Hukkinen, J., Roe, E., and Rochlin, G. I. (1990). "A salt on the land: A narrative analysis of the controversy over irrigation-related salinity and toxicity in California's San Joaquin Valley." Policy Sciences, 23(4), 307-329.

Hupe, P. L. (2011). "The Thesis of Incongruent Implementation: Revisiting Pressman and Wildavsky." Public Policy and Administration, 26(1), 63-80.

Iuchi, K. (2014). "Planning Resettlement After Disasters." Journal of the American Planning Association, 80(4), 413-425.

Jeong, H., Seo, H., and Kim, H. (2018). "Game Theory-Based Analysis of Decision Making for Coastal Adaptation under Multilateral Participation.” Journal of Management in Engineering, 34(6), 04018034.

Jones, D. S. (2009). "Curbing Corruption in Government Procurement in Southeast Asia: Challenges and Constraints." Asian Journal of Political Science, 17(2), 145-172.

Jones, M. D., and McBeth, M. K. (2010). “A Narrative Policy Framework: Clear Enough to Be Wrong?” Policy Studies Journal, 38(2), 329-353.

Jordan, E., Javernick-Will, A., and Tierney, K. (2016). "Post-tsunami recovery in Tamil Nadu, India: combined social and infrastructural outcomes." Natural Hazards, 84(2), 1327-1347.

Leech, N. L., Onwuegbuzie, A. J., and Link to external site, this link will open in a new window. (2007). "An array of qualitative data analysis tools: A call for data analysis triangulation." School Psychology, 22(4), 557-584.

Leech, N. L., Onwuegbuzie, A. J., and Link to external site, this link will open in a new window. (2011). "Beyond constant comparison qualitative data analysis: Using NVivo." School Psychology, 26(1), 70-84.

Manatunge, J. M. A., and Abeysinghe, U. (2017). "Factors Affecting the Satisfaction of Post-Disaster Resettlers in the Long Term: A Case Study on the Resettlement Sites of Tsunami-Affected Communities in Sri Lanka." Journal of Asian Development, 3(1), 94-124.

Min, J. H., Jang, W., Han, S. H., Kim, D., and Kwak, Y. H. (2018). "How Conflict Occurs and What Causes Conflict: Conflict Analysis Framework for Public Infrastructure Projects." Journal of Management in Engineering, 34(4), 04018019.

Molenaar, K. R., Songer, A. D., and Barash, M. (1999). "Public-Sector Design/Build Evolution and Performance." Journal of Management in Engineering, 15(2), 54-62.

Mosse, D. (2004). "Is Good Policy Unimplementable? Reflections on the Ethnography of Aid Policy and Practice." Development and Change, 35(4), 639-671. 
Naderpajouh, N., Yu, D. J., Aldrich, D. P., Linkov, I., and Matinheikki, J. (2018). "Engineering meets institutions: an interdisciplinary approach to the management of resilience." Environment Systems and Decisions, 38(3), 306-317.

NHA. (2018). "Updated Terms of Reference for the Procurement of Fully Developed Lots and Completed Housing Units Under the NHA’s Yolanda Permanent Housing Program.” National Housing Authority.

Nohrstedt, D., and Parker, C. (2014). "The Public Policy Dimension of Resilience in Natural Disaster Management: Sweden's Gudrun and Per Storms." Disaster and Development: Examining Global Issues and Cases, Environmental Hazards, N. Kapucu and K. T. Liou, eds., Springer International Publishing, Cham, 235-253.

OECD. (2014). Boosting Resilience through Innovative Risk Governance. OECD Reviews of Risk Management Policies, OECD.

Oliver-Smith, A. (1991). "Successes and Failures in Post-Disaster Resettlement." Disasters, 15(1), 12-23.

Oliver-Smith, A. (2020). "Resettlement for disaster risk reduction: Global knowledge, local application." Disaster upon disaster: exploring the gap between knowledge, policy, and practice, Catastrophes in context, S. M. Hoffman and R. E. Barrios, eds., Berghahn Books, New York, 198-217.

Olshansky, R. B., Hopkins, L. D., and Johnson, L. A. (2012). "Disaster and Recovery: Processes Compressed in Time." Natural Hazards Review, 13(3), 173-178.

Onwuegbuzie, A. J., Leech, N. L., and Collins, K. M. T. (2012). "Qualitative Analysis Techniques for the Review of the Literature." The Qualitative Report, 17(28), 30.

OPARR. (2014). "Yolanda Comprehensive Rehabilitation and Recovery Plan." Office of the Presidential Assistant for Rehabilitation and Recovery.

Opdyke, A., Javernick-Will, A., and Koschmann, M. (2017). "Infrastructure hazard resilience trends: an analysis of 25 years of research." Natural Hazards.

Opdyke, A., Javernick-Will, A., and Koschmann, M. (2018). "A Comparative Analysis of Coordination, Participation, and Training in Post-Disaster Shelter Projects." Sustainability, 10(11), 4241.

Orabi, W., Senouci, A. B., El-Rayes, K., and Al-Derham, H. (2010). "Optimizing Resource Utilization during the Recovery of Civil Infrastructure Systems." Journal of Management in Engineering, 26(4), 237-246.

O'Toole, L. J. (2000). "Research on Policy Implementation: Assessment and Prospects." Journal of Public Administration Research and Theory, 10(2), 263-288.

Pressman, J. L., and Wildavsky, A. (1984). Implementation: How Great Expectations in Washington Are Dashed in Oakland; Or, Why It's Amazing that Federal Programs Work at All, This Being a Saga of the Economic Development Administration as Told by Two Sympathetic Observers Who Seek to Build Morals on a Foundation. University of California Press.

Rama v. Moises. (2016). G.R. No. 197146.

Rasoulkhani, K., Mostafavi, A., Cole, J., and Sharvelle, S. (2019). "Resilience-based infrastructure planning and asset management: Study of dual and singular water distribution infrastructure performance using a simulation approach." Sustainable Cities and Society, 48, 101577.

RDC VIII. (2015). "RDC VIII Resolution No. 65, Series of 2015." National Economic and Development Authority.

Rew, A., Fisher, E., and Pandey, B. (2006). "Policy practices in development-induced displacement and rehabilitation." Development-induced displacement: Problems, policies and people, 18, 38-70.

Roe, E. (1994). Narrative policy analysis: theory and practice. Duke University Press, Durham.

Ruszczyk, H. A. (2019). “Ambivalence towards discourse of disaster resilience.” Disasters, 43(4), 818839.

Saetren, H. (2005). "Facts and Myths about Research on Public Policy Implementation: Out-of-Fashion, Allegedly Dead, But Still Very Much Alive and Relevant." Policy Studies Journal, 33(4), 559582.

Sanderson, D. (2017). "Implementing area-based approaches (ABAs) in urban post-disaster contexts." Environment and Urbanization, 29(2), 349-364. 
Sanderson, D., and Sharma, A. (2008). "Winners and losers from the 2001 Gujarat earthquake." Environment and Urbanization, 20(1), 177-186.

Schipper, L., and Pelling, M. (2006). "Disaster risk, climate change and international development: scope for, and challenges to, integration." Disasters, 30(1), 19-38.

Schofield, J. (2001). "Time for a revival? Public policy implementation: a review of the literature and an agenda for future research." International Journal of Management Reviews, 3(3), 245-263.

Schwab, J. (2014). Planning for post-disaster recovery: Next generation. Planning Advisory Service, American Planning Association.

Sutley, E. J., and Hamideh, S. (2017). "An interdisciplinary system dynamics model for post-disaster housing recovery." Sustainable and Resilient Infrastructure, 0(0), 1-19.

Tacloban City. (2014). "The Tacloban Recovery and Rehabilitation Plan."

Trump, B. D., Poinsatte-Jones, K., Malloy, T., and Linkov, I. (2019). "Resilience and risk governance: current discussion and future action." Handbook on Resilience of Socio-Technical Systems, M. Ruth and S. Goessling-Reisemann, eds., 136.

Tuhkanen, H., Boyland, M., Han, G., Patel, A., Johnson, K., Rosemarin, A., and Lim Mangada, L. (2018). "A Typology Framework for Trade-Offs in Development and Disaster Risk Reduction: A Case Study of Typhoon Haiyan Recovery in Tacloban, Philippines." Sustainability, 10(6), 1924.

USAID. (2015). Tacloban City North Bulk Water Supply Project Rapid Feasibility Study. USAID Be Secure Project Water Security for Resilient Economic Growth and Stability in the Philippines.

Welsh, M. (2014). "Resilience and responsibility: governing uncertainty in a complex world." The Geographical Journal, 180(1), 15-26. 